\title{
The Comparative Effect of Types of Contextual Clues on Iranian EFL Learners' Prediction of the Meaning of Unknown Vocabularies
}

\author{
Kolahi SH., Alikhademi Azam*, Kehtari M. \\ Islamic Azad University, Central Tehran Branch \\ *Corresponding author: a_alikhademi@yahoo.com
}

Received July 16, 2013; Revised Month July 27, 2013; Accepted July 31, 2013

\begin{abstract}
Understanding the meaning of unknown vocabularies has always been a great challenge for ESL/EFL learners. This study was an attempt to examine whether Iranian EFL learners' use of contextual clues has any significant impact on their knowledge of unknown vocabularies. The participants of the study were Sixty Iranian intermediate learners of Kish institute in Tehran, Iran. To homogenize the participants in terms of their English language proficiency Practice Tests (PET) was run Forty participants whose score fell one standard deviation above and below the mean were selected to take part in the study. The participants then were randomly divided in to two groups. A Reading test was administered at this stage to check if the participants' reading proficiency was not significantly different at the outset of the study. The experimental group received the treatment. Four types of contextual clue _ Explanation, Example, Antonym, Synonym _ were taught and practiced during ten sessions of instruction. The control group, on the other hand was taught based on the routine program with no emphasis on contextual clues. The reading section of another version of PET was administered as the post test. A t-test was run to analyze the results. The participants in the experimental group significantly outperformed those in the control group. The analysis of data revealed that knowledge and use of contextual clues has a significant impact on guessing the meaning of unknown vocabularies among Iranian EFL learners. Moreover, the researchers examined the comparative effect of types of contextual clue on learners' prediction of the meaning of unknown vocabularies. Their finding revealed that synonyms initially have the most effect. Then, explanations (definitions) and antonyms alternatively have effects on learners' prediction of the meaning of unknown vocabularies.
\end{abstract}

Keywords: types of contextual clues_explanation, example, antonym, synonym _ prediction of meaning, unknown vocabularies

Cite This Article: Kolahi SH., Alikhademi Azam, and Kehtari M., "The Comparative Effect of Types of Contextual Clues on Iranian EFL Learners' Prediction of the Meaning of Unknown Vocabularies” American Journal of Educational Research 1, no. 8 (2013): 272-278. doi: 10.12691/education-1-8-1.

\section{Introduction}

Students often have a lot of reading to do every day. They often come across word which they don't know its meaning. According [1] students have three choices to know the word's meaning and to understand what they are reading;

1. Look unfamiliar word up in the dictionary

2. Ask someone else what the words means

3. Try to figure out the sense of the word on their own

The first choice is not always viable because they may not have a dictionary with them while they are reading or there may not be that word in the dictionary. Also the dictionary may offer multiple meanings. The second one is easier but there may not be always someone nearby to ask or she/he likely requires contextual clues to say the meaning. They said that "Third choice encountering an unknown word is to hypothesize possible and logical senses of the word from its textual constraints (contextual clues)" [1] Unknown word is a word or phrase that the learner has either never seen before, or it is that she/he has only the vaguest idea about its meaning ([2] cited in Rappaport, 2003). According to ([3] cited in fan, 2003:222) "Vocabulary is the biggest part of meaning of any language and it is the biggest problem for most learners. Therefore, vocabulary learning is the real key to second language learning”. According to [4] contextual clues are in two varieties: first, semantic/syntactic and second is typographic. Semantic/ syntactic include:

1. Connected to synonyms

2. Contrasts

3. Cause and effects

4. Sequences

5. Definitions which are known with from of the verb "be"

6. Voice/mood which use more in poetry and fiction

7. Examples ("such as”), descriptors, and repeated information (in other words)

These can help readers predict words in several ways. [4] expressed that "knowing that a longer piece of text is 
discussing cause and effect help readers anticipate cue words like motivation, impetus, consequence"(p:25). If the context shows sequence, the readers might predict a word like chronologically; if it is the contrast context, readers might predict a word such as conversely. Typographic consists:
1. Glossary
2. Pictures
3. Food notes
4. Italics
5. Bold types
6. Graphs/charts
7. Parenthetical definitions

[1] referred to three kinds of specific contextual clues like appositives, parenthetic definitions and connecting text (e.g. "such as”, "an example of this is," "in contrast to").

[5] and [6] stated that there are different kinds of contextual clues. Examples: the context of a word will sometimes give examples that will give you a pretty clear idea of meaning or the meaning of on unknown word. Examples come after for example, for instance, like, such as, including, and e.g. or before and other. Definitions: sometimes the writer underlines the words in the sentences that signal the reader that some sort of definition is going to follow. Definitions may come after the expressions like that is, means or be. Another kind of definition is called an appositive_ is just a phrase that follows a word and explain it, sometimes this kind of phrase is set off on both sides by commas.

Synonyms: A context clue is often available in the form of a synonym that is put after comma (,) or dash (_) or in parentheses ( ). (Metaphor, a kind of symbol, is an important analytical concept).

Opposite/antonyms: words that mean the opposite of another word.

Antonyms are often signaled by words and phrases such as however, but on the other hand, in contrast, unlike, although, even though, except. These sentences, connectors show opposite or contrasting idea. (The box was cuber some, unlike the other light and easy-to-carry boxes.) General sense of the sentences: clues/ information's in the sentences what words might mean. Moreover, there are some other clues like the expressions "in other words" and "i.e". A reader may also infer a word's definition by using contextual clues combined with the reader's own experience, logic or knowledge.

Using contextual clues can be useful and important in different ways. Those readers who use contextual clues seem to be able to determine the meaning of unfamiliar words better [7]. It can accelerate the reader's reading rate. It also informs language learners on predicting unknown vocabulary. Using contextual clues seems to be an appropriate technique to help translators in guessing the meaning of the words. The result of this study can be useful for syllabus design especially in foreign language institutes and colleges. They can add some sessions to the reading courses and teach the learners contextual clues. It can help them to guess meaning of words and they also answer the questions in reading test better. It has some implications in language learning and teaching. For example: It is important sources of vocabulary learning [8]. Teaching contextual clues can enforce the learner's reading comprehension.
Some readers as English second language learners deal with different readings and contexts. In this case, one of the problems is although the learners read the whole texts and check the new words in the dictionary, they don't comprehend the real meanings. Second, having different meanings of words in the text lead to misunderstanding of learners because they may infer various meanings of the words regarding to their points of views. Third, learners face dilemma in their reading texts to guess the meaning of unknown words.

A number of studies have been conducted about the guessing of the meanings of the words from context and/or by using contextual clues $[2,7,9,10,11]$. According to [10]"Contextual clues can affect the process and outcome of word inference". Some studies show that learners use different types of contextual clues to different extent [10].

Hamanda (2009) examined word interference performance of English learners in reading and found that their strategies (sentences or contextual level strategies). [9] examined the role of the linguistic knowledge in inference the meanings of words and found that learners used both level cues (including grammatical and semantic cues) and wider co-text beyond sentence level to infer word meaning in reading. [2] conducted a research to compare the effectiveness of guessing vocabulary meaning from context (using contextual clues) and the bilingual word list method. Thirty seven 10-years-old ESL students participated in the study with two instructions, recall tests and interviews. The study revealed that bilingual word lists were more effective than guessing from context. Sometimes guessing from contexts was more useful than bilingual word list for vocabulary learning. Finally, language proficiency and age seem to correlate. More proficient learners were able to make better use of strategy and remember words learnt by guessing from context better while young female learners preferred bilingual word lists more and consider it more useful than guessing from context. [10] They identified three general types of contextual clues for lexical inference in reading comprehension: Local linguistic constituents (syntactic and semantic collocation), global text representations (text schemas and permanent memory) and word knowledge. They found that the most frequently used and effective clue was the local linguistic constituent, although learners would use different clues in combination. ([10]cited in Hynes, 1993) Hynes used two types of novel target word to investigate learner's word inference behavior in reading comprehension words with local cotext clues (words whose meanings could be inferred by using the immediate sentence context) and words with global co-text clues (words whose meanings could be infered by integrating information throughout the text). Hynes found that learners were quite more successful in inferring the meaning of words with local co-text clues than with global co-text clues. [7] conducted two studies to evaluate student's ability to use contextual clues in learning the meaning of unfamiliar words. In a descriptive study they examined the differential effects of form and proximity of contextual information on student's learning of unfamiliar words. This showed that students were better able to determine meaning of unfamiliar words when

a). Contextual clues were provided 
b). The clues were in synonym rather than inference form

c). Contextual clues were closer to the unknown word

d). Student were older

In an experimental study [7] examined the differential effects of three intervention strategies which facilitate the use of contextual information in learning the meanings of unfamiliar words. Its finding was rule-plus-systematicpractice and systematic- practice-only conditions produced higher transfer scores than a nonintervention condition.

Moreover, [11] investigated learning of word meanings from context during normal reading Three hundred and fifty two students who participated in this study read either expository or narrative passages selected from grade level textbooks. They were tested on their knowledge of difficult words from the passages. Effects of word and text properties on learning from context were examined is some detail. They started that "word properties investigated included length, morphological complexity, and part of speech. Text properties included the strength of contextual support for each word, readability as measured by standard formulas and several measures of density of difficult words." And "Among the word properties only conceptual difficulty was significantly related to learning from context. Among text properties, learning from context was most strongly influenced by the proportion of unfamiliar words that were conceptually difficult and by the average length of unfamiliar words" [11].

What the researchers have done in this study is to show whether or not using contextual clues have any statistically significant effect on predicting meaning of unknown vocabulary on EFL learners? Can those learners who use contextual clues predict the meanings of unfamiliar words better or not? Also, they examined to see what is the comparative effect of types of contextual clues on learners' prediction of the meaning of unknown vocabularies?

\section{Methodology}

The present study set out to investigate the effect of contextual clues on predicting meaning of unknown vocabularies and also the comparative effect of them on learners' prediction of the meaning of unknown vocabularies. It deals with explaining the participants, data collection and data analyses, instrument and the procedure employed to conduct the study.

\subsection{Participants:}

The participants of the study were female students who were selected from among a total number of 64 students studying at Kish English language institute in Tehran, Iran. They were all native speakers of Persian and were university students, university graduates or high school students with different majors. The participants were all females and their ages ranged from 15 to 30 . To homogenize the participants, sixty four students were selected and a proficiency test was administered because all of these students were at the intermediate levels and they had passed some reading comprehension courses. The mean score of the test result was calculated, and the students whose scores fell one standard deviation above and below the mean were selected for the study. They were randomly divided into two experimental and control groups.

\subsection{Proficiency Test:}

A proficiency test was administered to guarantee the participant's homogeneity in terms of their language proficiency level. According to the (Pet practice tests 2003) the proficiency tests consisted of two sub testes:

The first one was Reading comprehension part which required examinees to read some passages and to respond to some questions and writing part consisted of two parts, the first one was about writing only the missing words on their answer sheet and another one was writing a note about a topic. 45 minutes allotted to the test. Speaking and listening section were omitted because the researchers decided to focus on unknown vocabularies' meaning in writing and reading.

\subsection{Pre- testing the Knowledge of Contextual Clues: (Based on the PET tests)}

To assess the participant's performance regarding contextual clues-a pre-test was needed to be constructed. A researchers-made test of contextual clues was constructed to assess the performance of the participants on the target items in focus.

The pre test consisted of several reading comprehension from another version of PET. The pre-test required the learners to read the text and choose the correct word for each space and write the correct word in the gaps.

\subsection{Post- test of Contextual Clues:}

The post- test was administered to the two groups. According to the objective PEFT (2010), the post-test consisted of several reading passages on the basis of the types of contextual clues which were taught in the classes.

\subsection{Procedure:}

The data collection procedure went through various steps including the selection of the participants, giving proficiency test, pre- test, presenting the treatment, and the post-test.

\subsection{General English Proficiency Test:}

In the first step, the researchers administered a proficiency test based on the pet practice testes (2003) to homogenize the participants (64) regarding their proficiency level in English and out of 64 students, 40 participants whose scores fell between one standard deviation above and below the mean were selected as the participants of the study. Then, the participants were randomly divided in to two experimental and control groups.

\subsection{Pre-test:}

The pre-test of the study was administered in the very beginning session of the course see appendix in order to assess the initial behavior of the Persian speaking EFL 
learners who had never been trained in English contextual clues before.

In the third step, 40 homogenous learners were randomly assigned to two different groups (20 students each).

There were one experimental and one control group.

During the treatment phase of the study, the experimental group guessed the meaning of unknown vocabularies with some contextual clues techniques were taught. Another group_the control group_did not receive routine treatment. In some sessions, learners received some reading texts and examples which were mentioned after reading texts, while experimental group received some reading texts with types of contextual clues.

Types of contextual clues consist of:

1. Examples:

Examples are kind of clues to predict the meaning of the unknown words.

2. Definitions:

They can be as an appositive sentences or explanations.

3. Synonyms:

A word means as the same as unknown word.

4. Opposite/ antonyms:

Word that means what the word does not mean.

5. General sense of the sentence:

Clues in the sentences or surrounding the sentences about what words might mean.

Experimental group received treatment based on these contextual clues. More over at the beginning of each section learners were given a test about the previous section's materials.

At the end of whole sections they took general exam based on these techniques.

Students tried to do the exercises which consisted of learned contextual clues and were asked to make some new sentences with those contextual clues.

This procedure took about 1 hour of sessions, and the whole procedure took 10 sessions.

At the end of each session, learners take some quizzes on the use of contextual clues in understanding the meaning of unknown vocabularies. See appendixes A, B, C, D.

At the end of term students took the post test (objective pet 2010) the result was compared with the scores before the treatment, to see the difference before and after treatment. The pre-test and post-test were administered to the experimental and control groups.

Finally, a t-test was used to compare the mean scores of control and experimental group.

Moreover, the researchers examined the comparative effect of types of contextual clues (synonyms, definitions _explanations_, antonyms) on learners' prediction of the meaning of unknown vocabularies. They decided to employ a pilot test and also omitted examples and general sense of the sentence because they have limitations in their times and employment of the test. Then they corrected the tests related to each contextual clue separately. At the end "ANOVA" statistical method was employed to compare the means of each type of contextual clues' tests.

\section{Data Analysis}

The research question was formulated to examine whether contextual clues have any significant effect on predicting the meaning of unknown vocabularies by Iranian intermediate EFL learners. The descriptive statistics with the result of the T-test for the two groups are respectfully presented in Table 1 and Table 2.

Table 1. Descriptive statistics for the proficiency test (writing \& reading)

\begin{tabular}{|c|c|c|c|c|c|}
\hline Groups & $\mathrm{N}$ & Min & Max & Mean & Std. Deviation \\
\hline Experimental & 20 & 2 & 17.50 & 10.0500 & 3.75184 \\
\hline Control & 20 & 5 & 16 & 10.8250 & 3.32959 \\
\hline
\end{tabular}

Given the information in Table 1 there is a slight difference between the means; however, to make sure that this difference is not statistically significant, a t-test was run.

Table 2. T-test (Independent Samples Test)

\begin{tabular}{|c|c|c|c|}
\hline Groups & Mean & F & Sig \\
\hline Experimental & 10.05 & 00.0 & 0.99 \\
\hline Control & 10.82 & & \\
\hline
\end{tabular}

One can easily understand from Table 2 that the amount of the sig is more than 0.05 which is not statistically meaning full. Therefore, it can be said that the two groups were homogenous with regard to their proficiency level (reading, writing).

Table 3. Descriptive statistics for the pre-test

\begin{tabular}{|c|c|c|c|c|c|}
\hline Groups & $\mathrm{N}$ & Min & Max & Mean & SD \\
\hline Experimental & 20 & 5 & 13.50 & 8.5500 & 2.34465 \\
\hline Control & 20 & 2 & 13.00 & 6.9250 & 3.35714 \\
\hline
\end{tabular}

Table 3 reveals the descriptive statistics for the pre-test. The difference between the means revealed to be small; nevertheless, to find out if this difference is significant or not, so the T-test was employed.

Table 4. The result of T-test for pre-test

\begin{tabular}{|c|c|c|c|}
\hline Groups & Mean & F & Sig \\
\hline Experimental & 8.5 & \multirow{2}{*}{2.36} & 0.13 \\
\hline Control & 6.92 & & \\
\hline
\end{tabular}

Table 4 the amount of the sig is more than 0.05 which is not statistically meaningful.

Therefore, it can be claimed that the two groups were homogeneous in their knowledge of reading.

\subsection{Post-test result:}

Both the Control and the experimental group were given post-test, the performance of control group was compared with experimental group in post -test. Table 5 indicates the descriptive statistics for the post-test.

Table 5. Descriptive statistics for the post-test

\begin{tabular}{|c|c|c|c|c|c|}
\hline Groups & $\mathrm{N}$ & Min & Max & Mean & SD \\
\hline Experimental & 20 & 8.50 & 17.00 & 12.9000 & 2.28035 \\
\hline Control & 20 & 3 & 12.50 & 7.4000 & 2.97622 \\
\hline
\end{tabular}

T-test was employed between Experimental group and control group after treatment.

Table 6. The result of T-test for post-test

\begin{tabular}{|c|c|c|c|c|}
\hline Table 6. The result of T-test for post-test \\
\begin{tabular}{|c|c|c|c|c|}
\hline Groups & N & Mean & F & \multirow{2}{*}{0.00} \\
\hline Experimental & 20 & 12.9 & \multirow{2}{*}{6.56} & \\
\hline Control & 20 & 7.4 & & \\
\hline
\end{tabular}
\end{tabular}

Table 6 one can easily find out that the amount of tobserved is (t- observed $=6.56$ ) and the amount of the sig is less than 0.05 which doesn't have a statistically significant difference. In other words, contextual clues 
have significant effect on the EFL learners' predicting the meaning of unknown vocabularies in reading by EFL learners. Also these results of mean are shown in Figure 1.

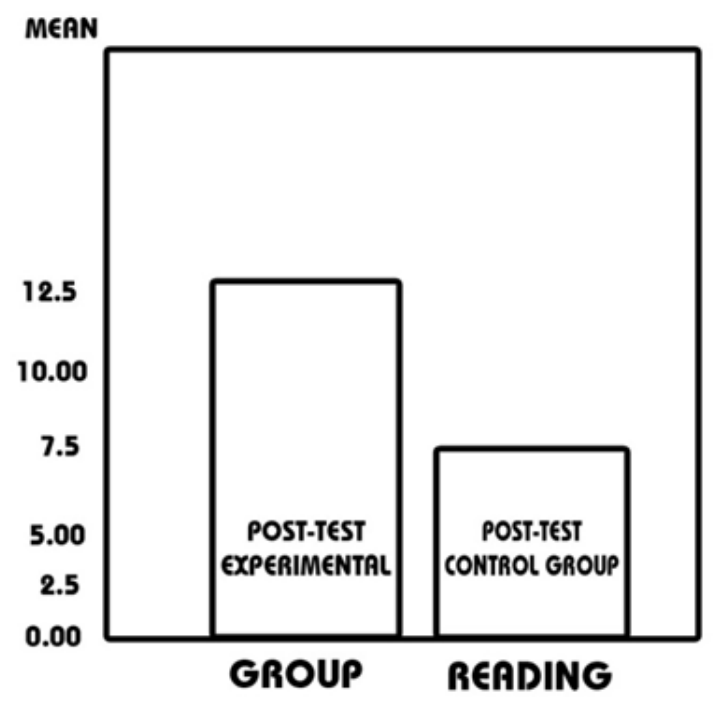

Figure 1. The result of T-test for post-test

The researchers decided to examine the effect of each type of contextual clues on learners' prediction of the meaning of unknown vocabularies. So, ANOVA Test was run.

Table 7. Donken Test

\begin{tabular}{|c|c|c|}
\hline \multicolumn{3}{|c|}{ Table 7. Donken Test } \\
\hline & F & Sig. \\
\hline Donken Test & 28.940 & .000 \\
\hline
\end{tabular}

As can be seen in Table 7, the comparison among means can be meaningful through employing Donken test because the amount of sig. is less than 0.05. In other words, the difference among means is meaningful.

Table 8. Table of comparison among means

\begin{tabular}{|c|c|c|c|}
\hline & Subjects & Mean & Synonym \\
\hline A & 20 & 5.9500 & Definition(explanation) \\
\hline B & 20 & 3.1500 & Antonym \\
\hline B & 20 & 2.7500 & letters \\
\hline
\end{tabular}

According to Table 8 anomalous letters indicate significant differences; for example, synonym differs from the other groups but definition and antonym do not have significant differences with regarding to descriptive statistic.

\section{Discussion}

The study was an attempt to examine the effects of contextual clues techniques on predicting meaning of unknown vocabularies of intermediate EFL learners. Thus, the main objectives of the study are: (a) to investigate the effect of contextual clues on predicting meaning of unknown vocabularies which contributed to improve the reading comprehension of different texts, and (b) to examine the effectiveness of certain types of contextual clues which require the learners guess the meaning of unfamiliar vocabularies in the text quickly. (c) to find the comparative effect of types of contextual clues on learners' prediction of the meaning of unknown vocabularies.

The previous study revealed that certain types of contextual clues, such as, antonym, synonym, example, explanation, etc.... are more effective on guessing meaning of unknown vocabularies, reading comprehension and listening comprehension like $[2,7,10]$.

These studies revealed that trained students can guess the meaning of vocabularies in reading faster than other students. Thus using contextual clues as you read is important for one reason.

1. You learned that even when you use the dictionary, it is often necessary to read several definitions of a word before you can find the one that fits the meaning of the sentence. So you will have to be alert to context clues even when you used the dictionary. [7] stated that "this strategy have a number of advantages over other strategies”. [8] proposed that "This strategy is the most important of all sources of vocabulary learning”.

The findings of this study strongly and positively are the same as the previous studies. For example, [7] examined the effects of contextual information on students learning of unknown words. They concluded that if contextual clues were provided and were in synonyms and were also closer to the unfamiliar word, the students were able to determine the meaning of unfamiliar words better.

\section{Conclusion}

This study attempts to investigate the effect of contextual clues on guessing meaning of unknown vocabularies and to examine the comparative effect of types of contextual clues (synonyms, definitions explanations-, antonyms) on learners' prediction of the meaning of unknown vocabularies. The findings of the study reveal that first, different types of contextual clues are significantly effective in better comprehension and understanding of unknown vocabularies in post-test. Moreover the learners were able to predict the meaning of unknown vocabularies better if contextual clues were alternatively synonyms, definitions-explanations-, antonyms.

Also, the findings of the study reveals that there are statistically significant differences between the experimental group, who received treatment, and the control group who do some exercise without regarding to the contextual clues.

\section{References}

[1] Dechert, D. A., Kibby, M. W., Rapaport, W.J., \& Wieland, K. M. (2002). Contextual Semantic Investigation for Word Meaning.University at Buffalo. Retrieved fromwww.cse.buffalo.edu/ rapaport/CVA

[2] TimTim, M. (2008). The effectiveness of guessing vocabulary meaning using contextual clues and learning word list in terms of vocabulary retention. (Unpublished dissertation). University of Hong Kong, Hong Kong.

[3] An Interview with Professor Michael McCarthy. (2001, May) Cambridge Connection, Hong Kong/ China Edition, 2, 1.

[4] Allen, J. (2006). Words, Words, Words: Teaching Vocabulary in Grades 4-12. Stenhouse.pp:24_26.

[5] Blass, L., Hartmann, P. (2007). Quest3 reading and writing ( $2^{\text {nd }}$ ed.). NewYork: McGrowHill Company

[6] Langon, J. (2008). Ten Steps to Improving College Reading Skills (5 $5^{\text {th }}$ ed.), 21_35.

[7] Carnine, D., Kameenui, E.J., \& Coyle, G. ( 1984). Utilization of Contextual Information in Determining the Meaning of Unfamiliar Words. Reading Research Quarterly, 19(2), 188-204. 
[8] Nation, I. S. P. (2001). Learning vocabulary in another language. Cambridge: Cambridge University Press.

[9] Alavi, M., \& Kaivanpanah, Sh. (2008). The role of linguistic knowledge in word-meaning inferencing. System, 36 (2), 172-195.

[10] Cai, W., \& Lee, B. (2010). Investigating the effect of contextual clues on the processing of unfamiliar words in second language listening comprehension. Australian Review of Applied Linguistics, $33(2)$.

[11] Anderson, R. C., Herman, P., \& Nagy, W. (1987). Learning Word Meanings from Context During Normal Reading. American Educational Research Journal, 24(2), 237- 270.

[12] Nagy, W., Herman, P. A., \& Anderson, R. C. (1985). Learning words from context. Reading Research Quarterly, 20(2), 233-253.

[13] Nagy, W. (1988). Teaching Vocabulary to Improve Reading Comprehension. Newark, DE: International Reading Association.

\section{Appendix A}

\section{Using Context Clues to Improve Reading Skills and Vocabulary Practice}

1. Raul is an indulgent father. For instance, He lets his daughter stay up as late as she likes and he never insists that she does het homework.
a) lazy and caring
b) stupid and kind
c) strict and mean
d) lenient and accepting

2. The child tried to placate the bully, doing everything he told her to do.
a) hate
b) satisfy
c)teach
d)fight

3. Even though Jardy enjoyed the movie and said it was exciting Danario thought it was tedious.
a) awesome
b)eventful
c)slow
d)boring

4. The mime troupe drama club and other local thespians will meet Saturday for a workshop.
a)organizations
b)singers
c)actors
d)workers

5. At first, the surgery seemed to be successful. However, several hours later the patient's condition began to deteriorate and it continued to worsen over the next few days.
a)stabilize
b)surprise everyone
c)change
d) decay or decline

6. Pewter is a combination of copper tin and antimony. The alloy is quite soft and presents some problems to a metal smith.
a)bowl
b)mixture of metals
c)hardware
d)chemical

7. Tom was oblivious to the noise but the rest of us were unable to concentrate on our work.
a)annoyed
b)frightened
c) unaware
d) bothered

8. The building obstructed our view as effectively as a blindfold.
a)helped
b)warmed
c)blocked
d)magnified

9. He could make the journey by mule cart, train or another conveyance.
a)adventure
c)vehicle
b)means of transporting
d)boat

10. The students were belligerent. In other words they did not listen to the teacher and often talked back to her.
a)argumentative
b)obedient
c)cruel
d)lazy

\section{Appendix B}

11. She sought redress for the wrong that had been done to her family.
a)correction
c)hope
b)promptness
d)repetition

12. The policeman examined the vicinity or area.
a)office
b)body
c)evidence
d)region

13. A combination of fog and industrial smoke called smog has vitiated the air in and around many big cities.
a)concentrated
b)filled up
c)replaced
d)contaminated

14. The vociferous crowd reminded me of the fans in the stands last year when we won the county championship who made it impossible to hear the trophy presentation.
a)respectful
b)quiet
c)enthusiastic
d)loud

15. Sedentary individuals people who are not very active often have diminished health.
a)immobile
b)sleepy
c)busy
d)boring

16. Earlier Caesar's men had tried and failed to invade Britain No doubt this contributed to the xenophobia of the Romans. They were cautious about strangers who entered their country.
a)honesty
c)kindliness
b)fear of foreigners
d)stubbornness

17. There is no doubt that the idea of living in such a benign climate was appealing. The islanders seemed to keep their vitality and live longer than Europeans.
a)tropical
b)favorable
c)harsh
d)warm

18. Ivan is a wonderful piano player but Jern is more versatile she sings, acts, paints and writes poetry and also plays the piano.
a)confident
b)skilled
c)talented
d)varied in abilities

19. Joan loves to buy exotic foods: vegetables and herbs from China spices from India, olives from Greece and cheeses from France.
a)expensive $\&$ tasty
b)highly and wise
c)selfish and mean
d)foreign \& unusual

20. The decision Veronica made to study instead of going out for pizza with her friends was prudent. She got an A on the exam, while her friends all got D's.
a)anti- social
b)careful and wise
c)selfish and mea
d)calculating

\section{Appendix C}

21. There is a large demand all over the United States for plants indigenous to the desert. Many people in Arizona have made a good business of growing and selling cacti and other local plants.
a)native
c)foreign
b)necessary
d)alien

22. Emotionally disturbed people may be troubled by morbid thoughts. For instance they may often think about suicide or murder.
a)fun and exciting
c)scary
b)ill and unhappy
d)gloomy and hopeless 
23. The purpose of the psychiatrist is to mitigate the suffering of the patient.
a)make milder
b)beautify
c)increase
d)banish

24. In Dickens A Christmas Carol the miserly Ebenezer Scrooge is visited by three spirits who changed him into a generous man.
a)single and elderly
b)unhappy
c)stingy
d)wealthy

25. My father died when I was a baby, but Mom told me so many stories about him that I feel I knew him. For instance one anecdote was about how he cried with joy when I was born.
a)joke
b)biographical account
c)example
d)banish

26. Unlike his quiet and low key family Brad is Garrulous.
a)friendly
b)sad
c)talkative
d)seaweed

27. The Asian gibbon like other apes is specially adapted for life in trees.
a)animal
b)monkey
c)tree
d)gorilla

28. Maya's quotation came from obscure book that even the teacher had never heard of.
a)lengthy
b)humorous
c)not well know
d)dusty

29. Brittany felt complacent about ner schoolwork because she had done well on every test,
a)unhappy
b)alarmed
c)rushed
d)satisfied

30.Unlike Chris who had player for many years. Angi was a novice on the count.
a)beginner
b)cnamp
c)friend
d)teacher

\section{Appendix D}

Choose the Best Option Which Has the Similar Meaning to the Sentence.
1. Every one angry that she was late. She arrived 2 hours late.

a) She turned up on time

b) She she turned up late

c) She turned up two hours sooner

2. Her secret was published in the media by the paparazzo who had taken her photos.

a) Some teenagers gave her photos to the media

b) Some people gave her photos to the media

c) Some photographers gave her photos to the media

3. When I told her the truth she was furious and started shouting at me.

a) She started crying

b) She was angry

c) She was cheerful and smiling

4. The obstetrician who told my mom that she was pregnant was a calm and nice woman. Obstetrician means.

a) A doctor for the birth of children

b) A nice and calm woman

c) A doctor for skin

5. You should never reveal your family problems and secrets to anyone. It means

a) You should disclose your family secrets to the public

b) It is not a good idea to tell people about your family secrets

c) People should ask you about your family secrets and then you tell them

6. The city was really vibrant. Everyone seemed lively and cheerful.

a) The city was quiet and boring

b) The city was full of life and energy

c) The city was peaceful and calm

7. Everything in the new system was great but the only small snag was the slow speed of the system, snag means

a) Advantage

b) Mistake

c) problem

8. Murder is a type of felony. Felony means

a) Mistake and disadvantage

b) crime

c) minor and unimportant offence 